\title{
Apparent Absorption Efficiencies of Nectar Sugars in the Cape Sugarbird, with a Comparison of Methods
}

\author{
Susan Jackson ${ }^{1, *}$ \\ Susan W. Nicolson ${ }^{1}$ \\ Ben-Erik van $\mathrm{Wyk}^{2}$ \\ ${ }^{1}$ Zoology Department, University of Cape Town, \\ Rondebosch 7700, South Africa; ${ }^{2}$ Botany Department, Rand \\ Afrikaans University, P.O. Box 524, Auckland Park 2006, \\ Johannesburg, South Africa
}

Accepted by G.K.S. 8/15/97

\begin{abstract}
Nectarivore sugar preferences and nectar composition in the Cape Floristic Kingdom (southern Africa) differ from trends reported for analogous systems in America and Europe in that sugarbirds and sunbirds show no aversion to sucrose, which is the dominant nectar sugar in many of their food plants. To elucidate the physiological bases (if any) of nectarivore sugar preferences, we determined apparent sugar absorption efficiencies in a passerine endemic to this region, the Cape sugarbird Promerops cafer. Apparent absorption efficiencies for the three major nectar sugars, sucrose, glucose, and fructose, were extremely high $(>99 \%)$, as in other specialized avian nectarivores. Xylose, a pentose sugar recently reported in the nectar of some Proteaceae, was absorbed and/or metabolized inefficiently, with a mean of $47.1 \%$ of ingested sugar recovered in cloacal fluid. We did not measure the proportions of xylose that were absorbed and/or metabolized. We also compared three methods of estimating absorption efficiency: (1) measurements of total sugar in cloacal fluid with refractometry, without correction for differences between volumes of ingesta and excreta; (2) the same measurements combined with correction for volume differences; and (3) HPLC analyses quantifying individual sugars in cloacal fluid, with correction for volume differences. Refractometry has been frequently used in previous studies. For all sugars except xylose, method 1 yielded results similar to those obtained with method 2 , but the convergence
\end{abstract}

${ }^{\star}$ To whom correspondence should be addressed. Present address: Department of Physiology, Wits Medical School, 7 York Road, Parktown 2193, South Africa; E-mail: 057sus@chiron.wits.ac.za.

Physiological Zoology 71(1):106-115. 1998. (C) 1998 by The University of Chicago. All rights reserved. 0031-935X/98/7101-9685\$03.00 was artifactual, and we do not recommend use of this method. Apparent absorption efficiencies calculated with method 2 underestimated true absorption efficiency, because refractometry measures nonsugar solutes, but this error is biologically significant only when efficiencies are low.

\section{Introduction}

Nectarivorous birds consume dilute solutions of sucrose, fructose, and glucose and apparently assimilate these sugars very efficiently. Absorption efficiencies (AE) of 97\%-99.5\% for the three sugars have been measured in three families of specialized nectarivores: American hummingbirds (Hainsworth 1974; Karasov et al. 1986; Martínez del Rio et al. 1988; Martínez del Rio 1990b), Australian honeyeaters (Collins and Morellini 1979; Collins et al. 1980), and African sunbirds (Lotz and Nicolson 1996). Of the above studies, two (Martínez del Rio 1990b; Lotz and Nicolson 1996) reported data for all three sugars, whereas the remainder used single sugars (sucrose or glucose).

The ability to absorb sucrose is not ubiquitous among birds and is, not surprisingly, linked to sugar preferences. Frugivorous passerines show apparent absorption efficiencies $\left(\mathrm{AE}^{*}\right)$ for sucrose that range from $0 \%$ (American robin, Turdus migratorius, and European starling, Sturnus vulgaris; Martínez del Rio and Stevens 1989; Karasov and Levey 1990) to 61\% (cedar waxwings, Bombycilla cedrorum; Martínez del Rio et al. 1989). These efficiencies are affected by differing activities of the intestinal disaccharidase sucrase, which must hydrolyze sucrose into its components glucose and fructose before absorption can occur (Martínez del Rio et al. 1989; Martínez del Rio 1990a), and by passage rates of fruit pulp through the gut, which influence the time available for this hydrolysis. Variation in $\mathrm{AE}^{\star} \mathrm{s}$ of sucrose is matched by sucrose aversions of varying intensity (Schuler 1983; Martínez del Rio et al. 1989; Brugger 1992).

Two of the three species of American nectar-consuming passerines that have been studied also avoid sucrose; yellowbreasted chats, Icteria virens, and yellow-winged caciques, Cacicus melanicterus, prefer hexoses to sucrose, whereas streakbacked orioles, Icterus pustulatus, are indifferent (Martínez del Rio et al. 1992). These preferences, coupled with the fact that passerine-pollinated plants in the genera Erythrina, Campsis, 
and Fuchsia produce hexose-dominated nectar in the Old World, led to a prediction that nectarivorous passerines in the Old World, like those in America, might prefer hexoses to sucrose (Martínez del Rio et al. 1992). However, recent findings necessitate revision of this comparison. Specialized passerine nectarivores from southern Africa, such as lesser double-collared sunbirds, Nectarinia chalybea, and Cape sugarbirds, Promerops cafer, are not averse to sucrose (Lotz and Nicolson 1996; Jackson et al. 1998), and the nectars of many of these birds' food plants (e.g., Erica spp.; Barnes et al. 1995) are sucrose-dominant.

The pentose sugar xylose was recently discovered in the nectar of Protea and Faurea species of the Proteaceae, a major ornithophilous family in southern Africa and Australia. Xylose comprises up to $39 \%$ of total nectar sugar in some species of these two genera (van Wyk and Nicolson 1995) but is rejected by both $N$. chalybea and $P$. cafer in choice tests (Lotz and Nicolson 1996; Jackson et al. 1998). This is surprising, because $P$. cafer has coevolved with the Proteaceae and is one of only two avian nectarivores endemic to the Cape Floristic Kingdom of southern Africa (fynbos).

On the basis of the above recently acquired information about their sugar preferences and the nectar composition of their food plants, we predicted that Cape sugarbirds would not show the poor sucrose AEs suggested by Martínez del Rio et al. (1992) for passerine nectarivores. We tested our prediction by comparing $\mathrm{AE}^{\star} \mathrm{s}$ of sucrose, glucose, and fructose in this species. We included xylose as a fourth sugar in our comparisons, because of its presence in Protea nectar.

The secondary aim of our study was a methodological comparison. Published studies of sugar $\mathrm{AE}^{\star} \mathrm{s}$ in nectarivores have employed different methods of measurement of excreted sugars. We therefore compared two commonly used refractometry methods of estimating sugar $\mathrm{AE}^{\star}$ s with a third technique, concurrent measurements of cloacal fluid sugars with HPLC.

\section{Material and Methods}

\section{Bird Capture and Maintenance}

Ten adult female Cape sugarbirds were caught during their nonbreeding season (March-April 1995 and October 1995) in mist nets and were housed separately in holding cages measuring $70 \times 80 \times 40 \mathrm{~cm}$ and covered with plastic-coated screen mesh (size, $2 \mathrm{~mm}$ ). Only females were used because the long tails of male sugarbirds would hamper their movements in the cages, and there is no a priori evidence supporting a sexlinked difference in diet or sugar $\mathrm{AE}^{\star}$ s. Birds were acclimated to captivity for 4-6 wk while housed outdoors. Two weeks before the feeding trials (see below), birds were moved to a laboratory partially lit by natural light.

The maintenance diet (Jackson et al. 1998) was made up of
$4.2 \mathrm{~g}$ each of sucrose, glucose, and fructose plus $2.5 \mathrm{~g}$ of Complan (Boots Pharmaceuticals, Isando, South Africa) per 100 $\mathrm{mL}$ of water. Complan is made from instant skim milk powder, corn syrup solids, vegetable oil, sucrose, lecithin, vitamins, and minerals, and its composition per $100 \mathrm{~g}$ is as follows (values calculated per wet weight): energy content, $1,818 \mathrm{~kJ}$; protein, 20 g; fat, $13.8 \mathrm{~g}$; carbohydrates, $56.7 \mathrm{~g}$; vitamin A, 2,682 IU; vitamin B6, $1.5 \mathrm{mg}$; vitamin B12, $4.5 \mu \mathrm{g}$; vitamin C, $72.4 \mathrm{mg}$; vitamin $\mathrm{D}, 150.9 \mathrm{IU}$; vitamin $\mathrm{E}, 8.6 \mathrm{IU}$; thiamine, $1.44 \mathrm{mg}$; riboflavin, $1.76 \mathrm{mg}$; Ca, $720 \mathrm{mg}$; Fe, $7.09 \mathrm{mg}$; biotin, $49.1 \mathrm{IU}$; folic acid, $192 \mu \mathrm{g}$; pantothenic acid, $4.7 \mathrm{mg}$; niacin, $10.9 \mathrm{mg}$; P, $587.3 \mathrm{mg} ; \mathrm{I}, 185.5 \mu \mathrm{g}$; Mg, $75.8 \mathrm{mg}$; Cu, $0.7 \mathrm{mg}$ Z, $7.1 \mathrm{mg}$; $\mathrm{Mn}, 0.9 \mathrm{mg}$; Na, $292.9 \mathrm{mg}$; and choline, $80.4 \mathrm{mg}$. The sugar concentration of this solution is thus $10.95 \%$. Unless otherwise stated, all references to relative solute masses and to solution concentrations (\%) are on a weight : weight basis (weight solute : total weight solution). The solution was presented to the birds ad lib. in plastic feeders and was changed twice daily. At the end of the experiments, the birds were banded and released at the site of capture. Additional housing details are given in Jackson et al. (1998).

\section{Experimental Procedure}

During tests for $\mathrm{AE}^{\star}$ (feeding experiments), we measured the volumes of food intake and of cloacal fluid production. To permit measurement of exact excreta volumes, we confined birds to cylindrical cages (diameter $36 \mathrm{~cm}$, height $50 \mathrm{~cm}$ ). While in these cages, birds fed ad lib. from glass feeders made from $25-\mathrm{mL}$ pipettes that permitted measurement of volumes remaining and, hence, estimation of volumes of liquid consumed to the nearest $0.05 \mathrm{~mL}$. The bottom ends of the pipettes were expanded to form glass bulbs $2.5 \mathrm{~cm}$ in diameter, with circular holes of diameter 4-5 $\mathrm{mm}$. These drinking apertures were surrounded by a 3-mm-wide ring of red nail varnish to enhance their visibility.

The protocol was as follows. Between 1700 and 1800 hours, we transferred individual birds from the holding cages to the cylindrical cages, weighing the birds in the process. At this time, we switched foods from the maintenance diet to a $20 \%$ sugar solution. Between 1320 and 1350 hours the following day, we noted the level of liquid in the feeders, replaced these with fresh feeders containing a measured volume of the same sugar solution, and slipped a plastic tray containing a $1.5-\mathrm{cm}$ layer of liquid paraffin under each cage. Both collection of cloacal fluid and measurements of food consumption commenced and ended simultaneously; after exactly $4 \mathrm{~h}$, we terminated the experiments by removing feeders and paraffin trays, weighing the birds, and transferring them back to their holding cages. This technique assumed equilibrium between drinking and defecation rates; we measured drinking rates and found that Cape sugarbirds drink at a constant hourly rate between 
1330 and 1730 hours. The 4-h fecal collection period is hereafter referred to as a feeding experiment, whereas the entire 24$\mathrm{h}$ period when the birds were confined to cylindrical cages is referred to as a feeding trial. One to two full days separated feeding trials for each bird, during which time it was fed the maintenance diet containing a mixture of sucrose, fructose, and glucose. The order of presentation of sugars to individual birds within the feeding trials was randomized. For all sugar types, the same 10 individual birds were used, except for xylose, for which a subset of five of these 10 was used.

We used 20\% aqueous solutions of sucrose, glucose, and fructose, and a glucose : fructose $(1: 1)$ mixture. We wished to investigate whether ingestion of the hexose combination, which contains sugars carried on two separate transporter systems (Sigrist-Nelson and Hopper 1974; Martínez del Rio $1990 b$ ), resulted in more efficient absorption of one or both sugars. The fifth solution used was a $20 \%$ xylose : glucose mixture in a ratio $(27: 73)$ approximating that of Faurea rochetiana (formerly Faurea speciosa) nectar, because this plant exhibits the highest naturally occurring levels of xylose yet reported (van Wyk and Nicolson 1995; B.-E. van Wyk and S. Nicolson, unpublished data). Pure xylose has harmful effects on Cape sugarbirds (Jackson et al. 1998) and so was not used.

\section{Cloacal Fluid Sugar Analyses}

All cloacal fluid voided by each bird was aspirated from under the liquid paraffin, its volume was measured with 10 - $\mathrm{mL}$ measuring cylinders accurate to the nearest $0.1 \mathrm{~mL}$, and the entire sample was then shaken thoroughly. Two subsamples of approximately $1.5 \mathrm{~mL}$ each were centrifuged at $11,000 \mathrm{rpm}$ for $2 \mathrm{~min}$ to separate particulate fecal matter. Aliquots of exactly $1 \mathrm{~mL}$ of the supernatant were taken with a Gilson micropipette. These samples were frozen for subsequent sugar analysis by HPLC (see below). A droplet of the remaining supernatant was used for measurement of sugar as sucrose equivalents with a hand-held refractometer (Bellingham \& Stanley Ltd.).

For each feeding experiment, HPLC analysis was carried out on two 1-mL subsamples of cloacal fluid applied in successive $25-\mu \mathrm{L}$ aliquots to filter paper. The samples were air-dried during and after each application and were stored at $-18^{\circ} \mathrm{C}$ before analysis. Cloacal fluid was recovered from the filter paper by rinsing with distilled water until no more sugar was detectable. Sugars were analyzed by isocratic HPLC operating at $2.5 \mathrm{~mL} /$ min with a Waters Sugarpack column, acetonitrile-water ( $87: 13)$ as eluent, and detection by refractive index. External standards were $8 \mathrm{mg} / \mathrm{mL}$ of the four sugars. Cloacal fluid concentrations were calculated in milligrams per milliliter by means of peak area.

We were concerned that bacterial action might alter the sugar composition of cloacal fluid during the 4-h feeding trials and during the time required for complete application and drying of cloacal fluid onto filter paper for HPLC. We therefore tested fresh cloacal fluid samples for bacterial contamination as follows. We fed a single bird a pure $20 \%$ glucose solution for the same period $(18 \mathrm{~h})$ that preceded the $\mathrm{AE}^{\star}$ feeding experiment (see above), after which time we collected a sample of cloacal fluid as soon as it was voided on a clean plastic sheet placed under the holding cage. Five $250-\mu \mathrm{L}$ aliquots of this sample were spiked with $20 \mu \mathrm{L}$ of a $1 \mathrm{~mol} / \mathrm{L}$ glucose solution and were incubated at room temperature for $0,2,4,6$, and $8 \mathrm{~h}$ before measurement of glucose content by the glucose oxidase method with a Beckman Glucose Analyzer 2 (Model 6517). Two separate $250-\mu \mathrm{L}$ aliquots were kept without glucose addition; one was analyzed immediately, and the other was incubated for $8 \mathrm{~h}$ before analysis. We presumed that bacterial action would cause a drop in the glucose content of the cloacal fluid from initial spiked levels, which would result in artificially elevated estimates of $\mathrm{AE}^{\star}$.

\section{Calculations}

We used three methods to estimate $\mathrm{AE}^{*}$, expressed as a percentage of sugar ingested. We did not quantify absorption of sugars from the gut directly but rather measured the fraction of ingested sugars that was excreted in the combined feces and urine (cloacal fluid). This fraction was expressed as a percentage of sugar excreted for methods 1 and 2, and as milligrams of sugar excreted for method 3 (below). Because in estimating this fraction we did not distinguish between endogenous sugars, lost in sloughed-off mucosal cells and in kidney filtrate, and ingested sugars that passed through the gut unabsorbed, the values that we report overestimate either the percentage or absolute amount of sugar in the cloacal fluid and thus underestimate "true" AEs. They are therefore given as $\mathrm{AE}^{\star} \mathrm{s}$. "Total sugar" refers to methods in which the sugars in cloacal fluid were not quantified separately, whereas "specific sugar" indicates that we distinguished between different sugars.

Method 1 (Total Sugar). This method of calculation of $\mathrm{AE}^{\star}$ has been used in the literature on nectarivores (Hainsworth 1974; Lotz and Nicolson 1996), and although it is inaccurate because it assumes equal volumes of water ingested and excreted (see Discussion), we wished to compare it with more precise methods. We did not base any conclusions on relative $\mathrm{AE}^{\star} \mathrm{s}$ of different sugars from estimates calculated with this method, which was included purely for validation purposes. We calculated $\mathrm{AE}^{\star}$ for this method as

$$
\mathrm{AE}^{\star}=100 \times\left(\% \operatorname{sugar}_{\text {in }}-\% \operatorname{sugar}_{\text {out }}\right) / \% \operatorname{sugar}_{\text {in }},
$$

where $\%$ sugar $_{\text {in }}$ and \% sugar ${ }_{\text {out }}$ are the percentages of sugar in the food and in the cloacal fluid, respectively, as measured by means of refractometry. 
Method 2 (Total Sugar). For this method, we calculated $\mathrm{AE}^{\star}$ as

$$
\begin{aligned}
\mathrm{AE}^{\star}= & 100 \times\left[\left(\% \operatorname{sugar}_{\text {in }} \times \operatorname{vol}_{\text {in }}\right)-\left(\% \operatorname{sugar}_{\text {out }} \times \operatorname{vol}_{\text {out }}\right)\right] / \\
& \left(\% \operatorname{sugar}_{\text {in }} \times \operatorname{vol}_{\text {in }}\right),
\end{aligned}
$$

where the percentages of sugar were measured as above, but where $\%$ sugar $_{\text {in }}$ and \% sugar ${ }_{\text {out }}$ were multiplied by the volumes $(\mathrm{mL})$ of food drunk ( $\left.\mathrm{vol}_{\mathrm{in}}\right)$ and of cloacal fluid excreted $\left(\mathrm{vol}_{\mathrm{out}}\right)$, respectively.

Method 3 (Specific Sugar). For this method, we calculated $\mathrm{AE}^{\star}$ as

$$
\mathrm{AE}^{\star}=100 \times\left(\mathrm{mg} \operatorname{sugar}_{\text {in }}-\mathrm{mg} \operatorname{sugar}_{\text {out }}\right) / \mathrm{mg} \operatorname{sugar}_{\mathrm{in}},
$$

where $\mathrm{mg}$ sugar $_{\text {in }}$ is the concentration $(\mathrm{mg} / \mathrm{mL})$ of sugar in food multiplied by the volume of food ingested $(\mathrm{mL})$ and $\mathrm{mg}$ sugar $_{\text {out }}$ is the sugar concentration $(\mathrm{mg} / \mathrm{mL})$ of cloacal fluid measured by means of HPLC, multiplied by cloacal fluid volume $(\mathrm{mL})$. The food solution was of known concentration $(20 \% \mathrm{w}: \mathrm{w})$. Because we measured volumes of sugar solution drunk, we calculated the concentration of each food solution as the product of the relative density of that sugar at $20^{\circ} \mathrm{C}$ $(\mathrm{mg} / \mathrm{mL})$ times 0.2 . Relative densities for $20 \%$ solutions of sucrose and fructose were taken from Wolf (1966), and we assumed that glucose and xylose solutions had the same relative density as did glucose.

To assess differences in $\mathrm{AE}^{\star}$ values between sugars within measurement methods and between the three measurement methods within sugars, we used repeated measures ANOVAs on arcsine-transformed $\mathrm{AE}^{\star} \mathrm{s}$, followed by post hoc TukeyKramer multiple comparisons to pinpoint the differences between pairs of values.

\section{Cloacal Fluid Osmolalities and Blood Xylose Analyses}

After five birds in their holding cages had fed ad lib. on $20 \%$ sucrose for $2 \mathrm{~h}$, we placed clean plastic sheets under their cages to collect droplets of cloacal fluid. The birds were continuously observed, and cloacal fluid was collected as soon as it was voided. The fluid was centrifuged at $11,000 \mathrm{rpm}$ for $2 \mathrm{~min}$, and the osmolality of the supernatant was measured with a Wescor 5500 vapor pressure osmometer. The osmolalities of cloacal fluid samples from four birds that had been fed a xylose : glucose (27: 73) mixture during the AE experiments were measured in the same way. Osmolalities of $20 \%$ sucrose and the xylose : glucose mixture were also measured. To investigate whether xylose was absorbed across the gut wall, we sampled blood and cloacal fluid from three birds $2 \mathrm{~h}$ after they had started feeding on the $20 \%$ xylose : glucose mixture described above. Blood was drawn by puncturing the brachial vein with a 24-gauge syringe needle after sterilization of the skin with $70 \%$ ethanol. We then held the tip of a heparinized $70-\mu \mathrm{L}$ hematocrit tube to the resulting droplet that formed on the skin. Bleeding stopped within $2 \mathrm{~min}$, and birds showed no ill effects. Blood and cloacal fluid were centrifuged at 11,000 rpm, and the xylose content of plasma and supernatant was measured by means of a colorimetric assay developed by the Chemical Pathology Laboratory at Groote Schuur Hospital. The assay involves incubation of $10-\mu \mathrm{L}$ aliquots of fluid with $1 \mathrm{~mL}$ of color reagent, containing $1 \mathrm{~g}$ phloroglucinol in 200 $\mathrm{mL}$ glacial acetic acid and $20 \mathrm{~mL}$ concentrated $\mathrm{HCl}$ for $4 \mathrm{~min}$ at $100^{\circ} \mathrm{C}$, followed by reading at $554 \mathrm{~nm}$ on a spectrophotometer.

\section{Results}

\section{Absence of Bacterial Depletion of Glucose in Cloacal Fluid}

The concentrations $(\mathrm{mmol} / \mathrm{L})$ of glucose in the cloacal fluid samples incubated after addition of $20 \mu \mathrm{L}$ of $1 \mathrm{~mol} / \mathrm{L}$ glucose per $2 \mathrm{~mL}$ cloacal fluid were as follows: without glucose, 0 ; spiked and incubated for $0 \mathrm{~h}, 11.8$; for $2 \mathrm{~h}, 12.2$; for $4 \mathrm{~h}, 12.2$; for $6 \mathrm{~h}, 12.0$; and for $8 \mathrm{~h}, 17.3$. Glucose is the sugar that is most easily assimilated and metabolized by bacteria; hence, we considered the constant concentration an indication that bacterial action was not affecting the concentrations of any of the sugars in cloacal fluid samples before HPLC analysis.

\section{Sugar $A E^{*} S$}

Comparison between Sugars. Mean $\mathrm{AE}^{\star}$ s for sucrose, glucose, fructose, and the glucose : fructose mixture were extremely high (Table 1). Xylose was apparently absorbed with significantly lower efficiency than were the other sugars, as is shown by repeated-measures ANOVAs on arcsine-transformed $\mathrm{AE}^{\star}$ values with method $2\left(F_{19}=167.67, P<0.0001\right)$ and method $3\left(F_{29}=279.8, P<0.0001\right)$. In this between-sugar comparison, we only used data for the five sugarbirds for which we had $\mathrm{AE}^{\star} \mathrm{s}$ for xylose as well as for the other three sugar types, because repeated-measures ANOVA demands matched samples. For method 2, post hoc Tukey-Kramer Multiple Comparisons yielded the following $q$-values for each pair of $\mathrm{AE}^{\star}$ s: glucose and xylose, $q=25.89$; fructose and xylose, $q=26.03$; sucrose and xylose, $q=25.77$ ( $P<0.001$ for all cases). For this method we did not calculate $\mathrm{AE}^{\star} \mathrm{s}$ of glucose and fructose in the glucose : fructose mixture, because refractometry does not distinguish between sugar types in cloacal fluid. For method 3, q-values for each pair of $\mathrm{AE}^{\star}$ s were as follows: glucose and xylose, $q=41.25$; fructose and xylose, $q=40.10$; glucose (in glucose : fructose mixture) and xylose, $q=42.45$; fructose (in glucose : fructose mixture) and xylose, $q=40.27$; and sucrose and xylose, $q=40.52(P<0.001$ for all cases $)$. 
Table 1: $\mathrm{AE}^{\star}$ s of different sugars in Cape sugarbirds, calculated by three methods

\begin{tabular}{|c|c|c|c|c|c|c|}
\hline \multirow[b]{3}{*}{ Method } & \multicolumn{6}{|c|}{ Sugar Type } \\
\hline & \multirow[b]{2}{*}{ Glucose } & \multirow[b]{2}{*}{ Fructose } & \multicolumn{2}{|c|}{$\begin{array}{l}\text { Glucose : Fructose } \\
\text { Mixture }\end{array}$} & \multirow[b]{2}{*}{ Sucrose } & \multirow[b]{2}{*}{ Xylose } \\
\hline & & & Glucose & Fructose & & \\
\hline $1 \ldots \ldots$ & $98.3(.4)$ & $98.2(.5)$ & $\ldots$ & . . & $98.6(.3)$ & $23.3(4.5)$ \\
\hline $2 \ldots \ldots . . .$. & $98.7(.3)$ & $98.6(.4)$ & $\ldots$ & $\ldots$ & $98.9(.3)$ & $37.3(5.0)$ \\
\hline $3 \ldots \ldots . . .$. & $99.9(.0)$ & $99.7(.1)$ & $100(.0)$ & $99.6(.1)$ & $99.7(.0)$ & $52.9(4.3)$ \\
\hline
\end{tabular}

Note. Method 1, measurement of cloacal fluid sugars by use of refractometry, with no measurement of cloacal fluid volumes. Method 2, measurement of cloacal fluid sugars by use of refractometry combined with measurement of both ingested and cloacal fluid volumes. Method 3, measurement of cloacal fluid sugars by use of HPLC, with measurement of both ingested and cloacal fluid volumes. For full explanation of the three methods, see Material and Methods. Values are given as percentages of original amount of sugar ingested, \pm 1 SE in parentheses. $n=10$ for all sugars except xylose, for which $n=5$.

The above analysis shows that among $\mathrm{AE}^{\star}$ s estimated with method 3, which measures specific sugars in the cloacal fluid, values for fructose and glucose when fed as a mixture were statistically indistinguishable from $\mathrm{AE}^{\star} \mathrm{s}$ for these sugars fed as pure solutions.

Birds consistently lost body mass during the feeding trials (mean mass lost among birds fed glucose, fructose, the glucose : fructose mixture, and sucrose was $0.7 \pm 0.2 \mathrm{~g}, 0.35 \pm 0.6 \mathrm{~g}$, $0.35 \pm 0.35 \mathrm{~g}$, and $0.6 \pm 0.19 \mathrm{~g}$, respectively). This was probably because of the stress of being moved between cages. Birds fed the xylose : glucose mixture lost a slightly higher fraction of their body mass $(1.2 \pm 0.12 \mathrm{~g})$, but this difference was not statistically significant (Friedman nonparametric repeatedmeasures test, $\mathrm{Fr}_{5}=6.773$ corrected for ties, $P>0.1$ ). For this comparison, we used only the five birds for which we had data for all five sugar solutions. The same five birds drank slightly but not significantly lower volumes of the xylose solution during the feeding experiments $\left(\mathrm{Fr}_{5}=7.2, P>0.1\right)$. The data used for this comparison were a subset of those used to calculate the means and SEs presented in Table 2, because we excluded the five birds that were not fed xylose to facilitate the use of the repeated-measures test.

Comparison between Methods. Four separate repeated-measures ANOVAs on arcsine-transformed $\mathrm{AE}^{\star} \mathrm{s}$ calculated with the three different methods showed overall significant differences between methods for each sugar (glucose: $n=10, F_{29}=3.066$, $P<0.05$; fructose: $n=10, F_{29}=11.05, P<0.001$; sucrose: $n=10, F_{29}=9.99, P<0.005$; and xylose: $n=5, F_{14}=15.63$, $P<0.001)$. Each ANOVA was followed by post hoc TukeyKramer comparisons, which showed that within each sugar type, $\mathrm{AE}^{\star} \mathrm{s}$ calculated with methods 1 and 2 were significantly lower than those calculated with method 3; methods 1 and 2 only differed significantly from one another in the case of xylose (glucose: comparison of methods 1 and $3, q=13.02$, $P<0.001$; comparison of methods 2 and $3, q=10.94, P$ $<0.001$; fructose: comparison of methods 1 and $3, q=6.33$, $P<0.001$; comparison of methods 2 and $3, q=4.93, P$ $<0.001$; sucrose: comparison of methods 1 and $3, q=6.02$, $P<0.01$; comparison of methods 2 and $3, q=4.68, P<0.05$; xylose: comparison of methods 1 and $2, q=7.10, P<0.01$; comparison of methods 1 and 3, $q=15.57, P<0.001$; comparison of methods 2 and $3, q=8.47, P<0.001$ ).

We regressed values for cloacal fluid sugars $(\mathrm{mg} / \mathrm{mL})$ measured by refractometry ( $y$-value) against corresponding values for each bird measured with HPLC ( $x$-value) and found the relationship to be linear and highly significant, with a slope of $1.25 \pm 0.04$ and a $y$-intercept of $2.44 \pm 0.53\left(r^{2}=0.97, P\right.$ $<0.0001)$. Refractometry thus overestimates cloacal fluid sugars by an average of $2.44 \mathrm{mg} / \mathrm{mL}$, which partly accounts for the underestimates of $\mathrm{AE}^{\star}$ calculated with methods 1 and 2 .

\section{Cloacal Fluid Osmolalities and Blood Xylose Analyses}

Birds fed a $20 \%$ pure sucrose solution (765 mOsmol/ $\mathrm{kg} \mathrm{H}_{2} \mathrm{O}$ ) excreted cloacal fluid with a mean osmolality of $72 \pm 8.1$ $\mathrm{mOsmol} / \mathrm{kg}(n=6)$. Birds fed a $20 \%$ xylose : glucose solution (total osmolality $=1,452 \mathrm{mOsmol}$, of which approximately $450 \mathrm{mOsmol} / \mathrm{kg}$ was xylose and 1,000 $\mathrm{mOsmol} / \mathrm{kg}$ was glucose) excreted cloacal fluid with a mean osmolality of $324 \pm 19.7$ $\mathrm{mOsmol} / \mathrm{kg}$ and total sugar content of $4.8 \% \pm 0.2 \%$ sucrose equivalents $(n=4)$. This sugar was presumably almost all xylose, because we measured the osmolality of pure $4.8 \%$ ( $\mathrm{w}: \mathrm{w}$ ) xylose and found it to be $335 \mathrm{mOsm} / \mathrm{kg}$. This corroborates the high glucose $\mathrm{AE}^{\star} \mathrm{s}$ reported above. The colorimetric assay revealed that xylose concentrations in the blood and cloacal fluid were $12.5 \pm 2.2$ and $228.7 \pm 36 \mathrm{mmol}$, respectively $(n=3), 2 \mathrm{~h}$ after the start of xylose ingestion. 
Table 2: Data used for calculation of $\mathrm{AE}^{\star}$ s of five $20 \%(\mathrm{w}: \mathrm{w})$ sugar solutions fed to Cape sugarbirds

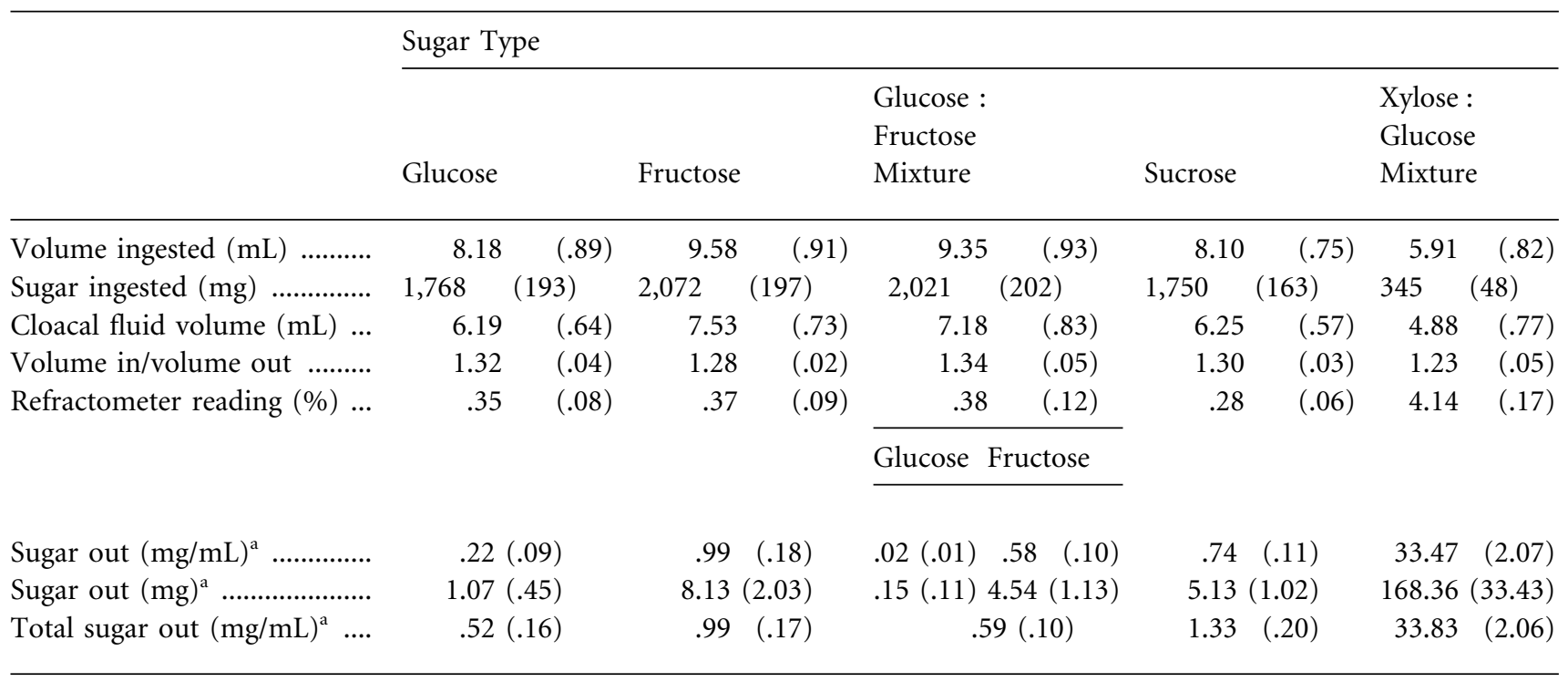

Note. Values are shown as means, followed by standard errors in parentheses. $n=10$ for all sugars except xylose, for which $n=5$. In mixed solutions, values for sugar out refer to the sugar of interest (glucose, fructose, or xylose), not to total sugar. Total sugar out refers to the sum of all sugars present in the cloacal fluid.

${ }^{\text {a }}$ Measured with HPLC.

\section{Discussion}

Although the major focus of our study was a comparison of $\mathrm{AE}^{\star} \mathrm{s}$ for different sugars in relation to food plant nectar composition, the results of our methodological validation dictate which data we used for this comparison. Therefore, we shall discuss methodological issues first, followed by the differences in $\mathrm{AE}^{\star} \mathrm{s}$ between sugars.

\section{Comparison of Methods of Measuring $A E^{*}$}

The $\mathrm{AE}^{*} \mathrm{~s}$ that we report are estimates of the amount of sugar retained by the birds, uncorrected for endogenous sugar losses via the gut and the kidneys. Table 3 shows that our values agree closely with true AEs for glucose in rainbow lorikeets, Trichoglossus haematodus (Karasov and Cork 1996), and for glucose, fructose, and sucrose in three species of hummingbirds (Karasov et al. 1986; Martínez del Rio 1990b). These AEs were measured in vivo with the double-isotope technique, which involves feeding a radio-labeled sugar of interest in conjunction with a nonabsorbable marker such as PEG-4000 that has been marked with a different isotope. Because this method measures recovery of marked sugars, the double-isotope technique avoids the bias introduced by excretion of endogenous sugars (Karasov et al. 1986; Martínez del Rio 1990b). The high degree of agreement between true AEs measured with this technique and the $\mathrm{AE}^{\star} \mathrm{s}$ for glucose, fructose, and sucrose that we obtained with method 3 suggests that the use of isotopes would not have altered our conclusions.
Method 1 (see, e.g., Hainsworth 1974; Lotz and Nicolson 1996) compared refractometer readings for food and cloacal fluid and assumed equal volumes of these fluids. This is an invalid assumption, because water is absorbed from the gut and either secreted via the kidneys or lost through respiration. Relatively high concentrations of sugars in cloacal fluid enhance the error caused by the difference between volumes of ingesta and excreta; therefore, $\mathrm{AE}^{*}$ s estimated with method 1 approached accuracy only when true AE was high. This is illustrated by the significant differences between xylose $\mathrm{AE}^{\star} \mathrm{s}$ that we obtained with the three methods. When $\mathrm{AE}^{\star}$ s are low, as are those reported for sucrose in some frugivorous passerines and for xylose in the present study, the artifactual nature of $\mathrm{AE}^{\star}$ estimates made with method 1 invalidates comparisons between sugars. We do not recommend use of this method.

Method 2, involving measurement of ingested and excreted volumes (see, e.g., Collins and Morellini 1979; Collins et al. 1980), yielded significantly higher $\mathrm{AE}^{\star}$ values for xylose than did method 1 but was effectively indistinguishable from method 1 for the more efficiently absorbed sugars. Method 2 was inaccurate because it does not partition cloacal fluid sugars, an error that will again be compounded when cloacal fluid sugar concentrations are high (i.e., when $\mathrm{AE}^{\star}$ s are low).

Method 3, in which ingested and excreted volumes were measured and the concentrations of each sugar in cloacal fluid were determined with HPLC, gave the most accurate results, and we recommend its use. There are two advantages to the use of HPLC. Unlike refractive index measurements (Inouye 
Table 3: Published AEs of three major nectar sugars in frugivorous and nectarivorous birds

\begin{tabular}{|c|c|c|c|c|c|}
\hline \multirow[b]{2}{*}{ Family and Species } & \multicolumn{3}{|l|}{$\mathrm{AE}(\%)$} & \multirow[b]{2}{*}{ Sucrase } & \multirow[b]{2}{*}{ Reference } \\
\hline & Sucrose & Fructose & Glucose & & \\
\hline \multicolumn{6}{|l|}{ Sturnidae: } \\
\hline European starling $\left(\right.$ Sturnus vulgaris) ${ }^{\mathrm{a}} \ldots .$. & $\begin{array}{l}\text { Presumably } \\
\text { low }\end{array}$ & $\begin{array}{l}\text { Presumably } \\
\text { high }\end{array}$ & $\begin{array}{l}\text { Presumably } \\
\text { high }\end{array}$ & Absent & $\begin{array}{l}\text { Martínez del Rio and } \\
\text { Stevens } 1989\end{array}$ \\
\hline \multicolumn{5}{|l|}{ Purple-headed glossy starling } & Malcarney et al. 1994 \\
\hline \multicolumn{6}{|c|}{ Muscicapidae: } \\
\hline American robin (Turdus migratorius) .... & 0 & $\cdots$ & 73 & Very low & $\begin{array}{l}\text { Karasov and Levey } \\
1990\end{array}$ \\
\hline \multicolumn{6}{|l|}{ Mimidae: } \\
\hline \multicolumn{6}{|l|}{ Gray catbird (Dumutella } \\
\hline 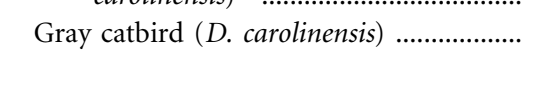 & Low & $\cdots$ & High & 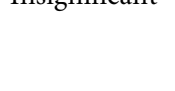 & $\begin{array}{l}\text { Karasov and Levey } \\
1990\end{array}$ \\
\hline \multicolumn{6}{|l|}{ Bombycillidae: } \\
\hline $\begin{array}{l}\text { Cedar waxwing (Bombycilla } \\
\text { cedrorum) }\end{array}$ & 61 & 88 & 92 & High & $\begin{array}{l}\text { Martínez del Rio et al. } \\
\quad 1989\end{array}$ \\
\hline \multicolumn{6}{|l|}{ Emberizidae: } \\
\hline $\begin{array}{l}\text { Common grackle (Quiscalus } \\
\text { quiscula) })^{\mathrm{e}}\end{array}$ & $\begin{array}{l}\text { Presumably } \\
\text { high }\end{array}$ & $\begin{array}{l}\text { Presumably } \\
\text { high }\end{array}$ & $\begin{array}{l}\text { Presumably } \\
\text { high }\end{array}$ & Highest & $\begin{array}{l}\text { Martínez del Rio et al. } \\
\quad 1988\end{array}$ \\
\hline $\begin{array}{l}\text { Redwinged blackbird (Agelaius } \\
\text { phoeniceus) })^{\mathrm{e}}\end{array}$ & $\begin{array}{l}\text { Presumably } \\
\text { high }\end{array}$ & $\begin{array}{l}\text { Presumably } \\
\text { high }\end{array}$ & $\begin{array}{l}\text { Presumably } \\
\text { high }\end{array}$ & Intermediate & $\begin{array}{l}\text { Martínez del Rio et al. } \\
1988\end{array}$ \\
\hline \multicolumn{6}{|l|}{$\begin{array}{l}\text { Black-chinned hummingbird (Archilocus } \\
\text { alexandri): }\end{array}$} \\
\hline Female & 99 & $\ldots$ & $\ldots$ & & Hainsworth 1974 \\
\hline Male & $97-98.5$ & $\ldots$ & $\ldots$ & & Hainsworth 1974 \\
\hline \multicolumn{6}{|l|}{ Blue-throated hummingbird (Lampornis } \\
\hline 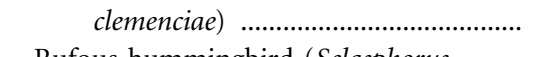 & $97.5-99$ & $\cdots$ & $\cdots$ & & Hainsworth 1974 \\
\hline $\begin{array}{l}\text { Rufous hummingbird (Selasphorus } \\
\text { rufous) }\end{array}$ & $\cdots$ & $\cdots$ & $97.1 \pm .3$ & & Karasov et al. 1986 \\
\hline Rufous hummingbird (S. rufous) ............ & $\cdots$ & $\cdots$ & $>97$ & & $\begin{array}{l}\text { Martínez del Rio et al. } \\
1988\end{array}$ \\
\hline Anna's hummingbird (Calypte anna) .... & $\cdots$ & $\cdots$ & $>97$ & & $\begin{array}{l}\text { Martínez del Rio et al. } \\
1988\end{array}$ \\
\hline $\begin{array}{l}\text { Cinnamon hummingbird (Amazilia } \\
\text { rutilia) }\end{array}$ & $97 \pm 1$ & $97 \pm 2$ & $99 \pm 1$ & & $\begin{array}{l}\text { Martínez del Rio } \\
\quad 1990 b\end{array}$ \\
\hline $\begin{array}{l}\text { Broad-billed hummingbird } \\
\qquad \text { (Cynanthus latirostris) }\end{array}$ & $99 \pm 1$ & $98 \pm 1$ & $97 \pm 2$ & & $\begin{array}{l}\text { Martínez del Rio } \\
\quad 1990 b\end{array}$ \\
\hline $\begin{array}{l}\text { Fork-tailed emerald } \\
\qquad(\text { Chlorostilbon caniveti }) \text {........................ }\end{array}$ & $98 \pm 2$ & $97 \pm 3$ & $99 \pm 1$ & & $\begin{array}{l}\text { Martínez del Rio } \\
\quad 1990 b\end{array}$ \\
\hline \multicolumn{6}{|l|}{ Meliphagidae: } \\
\hline $\begin{array}{l}\text { Brown honeyeater (Lichmera } \\
\quad \text { indistincta) ......................................... } \\
\text { Singing honeyeater (Meliphaga }\end{array}$ & $98-99.5$ & $\cdots$ & $\cdots$ & & Collins et al. 1980 \\
\hline 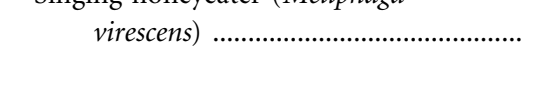 & $97-98.7$ & $\cdots$ & $\cdots$ & & $\begin{array}{l}\text { Collins and Morellini } \\
1979\end{array}$ \\
\hline
\end{tabular}


Table 3 (Continued)

\begin{tabular}{|c|c|c|c|c|c|}
\hline \multirow[b]{2}{*}{ Family and Species } & \multicolumn{3}{|l|}{$\mathrm{AE}(\%)$} & \multirow[b]{2}{*}{ Sucrase } & \multirow[b]{2}{*}{ Reference } \\
\hline & Sucrose & Fructose & Glucose & & \\
\hline \multicolumn{6}{|l|}{ Nectariniidae: } \\
\hline $\begin{array}{l}\text { Lesser double-collared sunbird } \\
\qquad(\text { Nectarinia chalybea })\end{array}$ & 96.9 & 97.9 & 96 & & $\begin{array}{l}\text { Lotz and Nicolson } \\
1996\end{array}$ \\
\hline \multicolumn{6}{|l|}{ Promeropidae: } \\
\hline $\begin{array}{l}\text { Cape sugarbird (Promerops cafer) ……..... } \\
\text { Psittacidae: }\end{array}$ & $99.7 \pm .04$ & $99.7 \pm .06$ & $99.9 \pm .03$ & & This study \\
\hline $\begin{array}{l}\text { Rainbow lorikeet (Trichoglossus } \\
\text { haematodus) }\end{array}$ & $\cdots$ & $\cdots$ & $98.0 \pm .4$ & & $\begin{array}{l}\text { Karasov and Cork } \\
1996\end{array}$ \\
\hline
\end{tabular}

Note. All values are expressed as percentages of ingested sugars. Where sucrase values are omitted, they were not measured. Ellipses, no data.

${ }^{a} \mathrm{AE}$ was not measured directly, but measured blood glucose increased after fructose and glucose meals and not after sucrose meals, implying low AE for the latter.

b These authors measured fecal sugars but not excreta volumes and reported AEs for glucose and fructose in a nonquantitative fashion.

${ }^{\mathrm{c}}$ Maltase levels very high: 200 times sucrase levels.

"Reported as "similar to American robin"; that is, close to 0 for sucrose and high for glucose.

e AE was not measured directly, but blood glucose increased after sucrose, fructose, and glucose meals, which implies measurable AEs for all three sugars.

et al. 1980), HPLC analysis is unaffected by substances other than sugars in cloacal fluid, and it permits calculation of $\mathrm{AE}^{\star} \mathrm{s}$ for individual sugars in mixtures. Our data (Table 2) show that sugars in cloacal fluid measured by refractometry (from $0.28 \%-4.14 \%$ ) were higher than corresponding HPLC values for total sugar excreted (in units of millgrams per milliliters, converted to percentages by division by $10 ; 0.05 \%-3.38 \%$ ). This discrepancy reflected measurement of nonsugar solutes in the cloacal fluid by refractometry and is another reason for the underestimation of $\mathrm{AE}$ estimates by methods 1 and 2 . Refractometer estimates can be corrected by use of the linear regression of cloacal fluid sugars measured with refractometry on values measured with HPLC, which here had a slope of $1.25 \pm 0.04$ and a $y$-intercept of $2.44 \pm 0.53 \mathrm{mg} / \mathrm{mL}$. The slope was greater than unity; therefore, the higher the concentration of sugars, the greater the magnitude of their overestimation by refractometry. This adds strength to our recommendation that when expected $\mathrm{AE}^{\star} \mathrm{s}$ are low, methods of measurement more accurate than refractometry should be used.

Because of its superior accuracy, we base all our comparisons (below) of $\mathrm{AE}^{\star}$ s between different sugars on method 3 .

\section{African Passerine Nectarivores Absorb Sucrose and Hexoses with Equal Efficiency}

Unlike passerine frugivores, sugarbirds and sunbirds assimilate sucrose, glucose, and fructose with equally high efficiencies (Lotz and Nicolson 1996; this study). This is not unexpected, because their food plants secrete nectar containing all these sugars (Barnes et al. 1995; van Wyk and Nicolson 1995). The sucrose $\mathrm{AE}^{\star} \mathrm{s}$ that we report are similar to published values for both passerine (Australian honeyeaters, Meliphagidae) and nonpasserine nectarivores (American hummingbirds, Trochilidae; Table 3). In both the New and Old Worlds, nectarivory thus favors high $\mathrm{AE}^{\star} \mathrm{s}$ of the three most frequently encountered nectar sugars.

High sucrose $\mathrm{AE}^{\star} \mathrm{s}$ are coupled with a preference for this sugar in lesser double-collared sunbirds (Lotz and Nicolson 1996) or with an equal liking for sucrose and the hexoses (Cape sugarbirds; Jackson et al. 1998). Ingestion of sucroserich nectar may result in faster delivery of energy to the intestine, because solutions of high concentration slow gastric emptying; Karasov and Cork (1996) found that gastric emptying of glucose slows with increasing concentration in nectarivorous rainbow lorikeets. A $20 \%$ sucrose solution is equicaloric with a $20 \%$ hexose solution but has only half the osmotic concentration $(765 \mathrm{mOsmol} / \mathrm{kg}$ compared with 1,372 and $1,397 \mathrm{mOs}-$ $\mathrm{mol} / \mathrm{kg}$ for glucose and fructose, respectively) and is probably emptied from the birds' stomachs more rapidly. We do not know the degree to which this energetic advantage of sucrose is offset by the time taken for hydrolysis before this sugar can absorbed.

HPLC analysis often detected fructose in the cloacal fluid of sugarbirds that had fed on pure glucose for $24 \mathrm{~h}$. The same has been found in sunbirds (C. N. Lotz and S. W. Nicolson, unpublished data). Presumably because it is slowly metabolized, some of this sugar is retained in the body and excreted over a period longer than $24 \mathrm{~h}$, and the fructose that we detected in cloacal fluid originated in sugars fed to the birds 
before the start of the feeding trials. Fructose must undergo gluconeogenesis in the liver before being metabolized by birds (Martínez del Rio et al. 1989) and is less readily oxidized than is glucose during exercise in human athletes (Massicotte et al. 1986). Fructose ingestion causes less insulin release than does glucose ingestion (Massicotte et al. 1986), and, consequently, rises in blood glucose are slower after fructose than after glucose ingestion. Small amounts of fructose may thus remain unmetabolized in the blood, with slow excretion rates accounting for the residues that we observed.

Glucose and fructose cross the intestinal mucosa on independent transporter systems (Sigrist-Nelson and Hopper 1974). Martínez del Rio (1990b) suggested that $1: 1$ mixtures of these two hexoses might be absorbed faster and more efficiently by the intestine than equicaloric single sugar solutions, because sugars from the former solutions are being absorbed by two transporter systems working simultaneously. We found no difference in $\mathrm{AE}^{\star} \mathrm{s}$ when fructose and glucose were fed singly or as a mixture, but comparison of intestinal absorption rates between these solutions is needed to more fully address this issue. If passive absorption of sugars in the intestine is more important than has been previously supposed (Karasov and Cork 1994; see below), active transport rates may have less influence on $\mathrm{AE}^{\star}$ than do the osmotic concentrations of sugars in the lumen.

\section{Xylose Absorption in Sugarbirds}

In contrast to the other three sugars that we studied, xylose appears to have little or no energetic value to Cape sugarbirds; hence, the reason for its occurrence in Protea and Faurea nectar is unclear. Although our data do not indicate whether or not xylose is absorbed efficiently, its high concentrations in cloacal fluid suggest poor absorption, or poor metabolism, or both. Xylose is not known to be metabolized by vertebrates (Zilva and Pannall 1984), is unpalatable to the three southern African nectarivores that have been studied so far (Lotz and Nicolson 1996; Franke et al. 1998, Jackson et al. 1998), and causes distress in Cape sugarbirds if consumed as a pure $20 \%$ solution (Jackson et al. 1998). However, the concentration that we used (5.4\% in a solution of $20 \%$ total sugar, with glucose comprising the remaining $14.6 \%$ ) probably did not cause osmotic diarrhea, because cloacal fluid volume did not increase relative to volume of food consumed (Table 2). Cloacal-fluid osmolalities in xylose-fed birds approached the osmolalities of the xylose component of the ingested solution. Although we did not quantify the amount of xylose that crossed into the blood, we presume that this fraction accounted for the difference between ingested and excreted concentrations of xylose and was excreted via the kidneys after the conclusion of our experiments. True AE for this sugar would be best measured with labeled xylose.

The mechanism of intestinal absorption of xylose was proba- bly passive. Glucose and fructose are absorbed across the intestinal mucosa by means of specific active transporters (Karasov and Diamond 1983), but recent studies using the isomer Lglucose have shown that passive (non-carrier-mediated) absorption of glucose constitutes up to $80 \%$ of total uptake in rainbow lorikeets (Karasov and Cork 1994). Although the passive permeability of Cape sugarbird intestines to sugars is not known, it is probably comparable to that of other nectarivores such as the rainbow lorikeet (Karasov and Cork 1994). In the absence of a known xylose transporter, we presume that the xylose that we report in the plasma of Cape sugarbirds was absorbed passively via the paracellular spaces of the mucosa.

\section{Acknowledgments}

We thank Cape Nature Conservation for permission to capture birds, Donella Young for helping with their care, and Dr. Peter Berman (Department of Chemical Pathology, University of Cape Town Medical School) for help with xylose assays. Generous financial support was provided by the South African Foundation for Research Development and by the University of Cape Town in the form of a "Brain Gain" postdoctoral award to S.J. and S.W.N.

\section{Literature Cited}

Barnes K., S.W. Nicolson, and B.-E. van Wyk. 1995. Nectar sugar composition in Erica. Biochem. Syst. Ecol. 23:419423.

Brugger K.E. 1992. Repellency of sucrose to captive American robins. J. Wildl. Manag. 56:794-799.

Collins B.G., G. Cary, and G. Packard. 1980. Energy assimilation and storage by the brown honeyeater, Lichmera indistincta. J. Comp. Physiol. 137:157-163.

Collins B.G. and P.C. Morellini. 1979. The influence of nectar concentration and time of day upon energy intake and expenditure by the singing honeyeater, Meliphaga virescens. Physiol. Zool. 52:165-175.

Franke E.S., S. Jackson, and S.W. Nicolson. 1998. Nectar sugar preferences and absorption in a generalist African frugivore, the Cape white-eye Zosterops pallidus. Ibis (in press).

Hainsworth F.R. 1974. Food quality and foraging efficiency: the efficiency of sugar assimilation by hummingbirds. J. Comp. Physiol. 88:425-431.

Inouye D.W., N.D. Favre, J.A. Lanum, D.M. Levine, J.B. Myers, M.S. Roberts, F.C. Tsao, and Y.-Y. Wang. 1980. The effects of nonsugar nectar constituents on estimates of nectar energy content. Ecology 61:992-996.

Jackson, S., S.W. Nicolson, and C. Lotz. 1998. Sugar preferences and "side bias" in Cape sugarbirds and lesser double-collared sunbirds. Auk 115:156-165.

Karasov W.H. and S.J. Cork. 1994. Glucose absorption in a 
nectarivorous bird: the passive pathway is paramount. Am. J. Physiol. 267:G18-G26.

- 1996. Test of a reactor-based digestion optimization model for nectar-eating rainbow lorikeets. Physiol. Zool. 69:117-138.

Karasov W.H. and J.M. Diamond. 1983. Adaptive regulation of sugar and amino acid transport by vertebrate intestine. Am. J. Physiol. 245:G443-G462.

Karasov W.H. and D.J. Levey. 1990. Digestive system tradeoffs and adaptations in frugivorous passerine birds. Physiol. Zool. 63:1246-1270.

Karasov W.H., D. Phan, J.M. Diamond, and F.L. Carpenter. 1986. Food passage and intestinal nutrient absorption in hummingbirds. Auk 103:453-464.

Lotz C.N. and S.W. Nicolson. 1996. Sugar preferences of a nectarivorous passerine bird, the lesser double-collared sunbird (Nectarinia chalybea). Funct. Ecol. 10:360-365.

Malcarney H.L., C. Martínez del Rio, and V. Apanius. 1994. Sucrose intolerance in birds: simple nonlethal diagnostic methods and consequences for assimilation of complex carbohydrates. Auk 111:170-177.

Martínez del Rio C. 1990a. Dietary, phylogenetic, and ecological correlates of intestinal sucrase and maltase activity in birds. Physiol. Zool. 63:987-1011.

— 1990b. Sugar preferences in hummingbirds: the influence of subtle chemical differences on food choice. Condor 92:1022-1030.

Martínez del Rio C., H.G. Baker, and I. Baker. 1992. Ecological and evolutionary implications of digestive processes: bird preferences and the sugar constituents of floral nectar and fruit pulp. Experientia 48:544-550.

Martínez del Rio C., W.H. Karasov, and D.J. Levey. 1989. Physiological basis and ecological consequences of sugar preferences in cedar waxwings. Auk 106:64-71.

Martínez del Rio C. and B.R. Stevens. 1989. Physiological constraint on feeding behavior: intestinal membrane disaccharidases of the starling. Science 243:794-796.

Martínez del Rio C., B.R. Stevens, D.E. Daneke, and P.T. Andreadis. 1988. Physiological correlates of preference and aversion for sugars in three species of birds. Physiol. Zool. 61:222-229.

Massicotte D., F. Péronnet, C. Allah, C. Hillaire-Marcel, M. Ledoux, and G. Brisson. 1986. Metabolic response to $\left[{ }^{13} \mathrm{C}\right]$ glucose and $\left[{ }^{13} \mathrm{C}\right]$ fructose ingestion during exercise. J. Appl. Physiol. 61:1180-1184.

Schuler W. 1983. Responses to sugars and their behavioural mechanisms in the starling (Sturnus vulgaris L.). Behav. Ecol. Sociobiol. 13:243-251.

Sigrist-Nelson K. and U. Hopper. 1974. A distinct D-fructose transport system in isolated brush-border membrane. Biochim. Biophys. Acta 367:247-254.

van Wyk B.-E. and S.W. Nicolson. 1995. Xylose is a major nectar sugar in Protea and Faurea. S. Afr. J. Sci. 91:151153.

Wolf A.V. 1966. Aqueous Solutions and Body Fluids: Their Concentrative Properties and Conversion Tables. Harper \& Row, New York.

Zilva J.F. and P.R. Pannall. 1984. Clinical Chemistry in Diagnosis and Treatment. 4th ed. Lloyd-Luke, London. 